\title{
Information Inadequacy: The Lack of Needed Information in Human, Social and Industrial Affairs
}

\author{
Miranda Kajtazi \\ Linnaeus University, School of Computer Science, Physics and Mathematics, Växjö, Sweden \\ miranda.kajtazi@lnu.se
}

\begin{abstract}
This study investigates the phenomenon of the lack of needed information, predominantly experienced through difficulties in human, social and industrial affairs. The key concern is, thus, to understand what really causes the lack of needed information. Answers to this concern have been provided from an array of studies mostly focused in the area of information management. However, the literature shows that there is no comprehensive a priori theory to guide an empirical investigation on this matter. Thus, the empirical investigation conducted here is based on grounded theory approach that investigates fifty cases, where the lack of needed information is clearly manifested. The empirical investigation suggests that the phenomenon of the lack of needed information seems to emerge because of diverse factors, ranging from political and cultural structures, through human individual capabilities, and ending with procedural and technological artefacts. The results present an initial outline for a possible future theory of information inadequacy.
\end{abstract}

Keywords: information inadequacy, information management, information needs, information retrieval.

\section{Introduction}

Some fundamental questions in contemporary debates about the information society are concerned with phenomena that relate to information problems, predominantly experienced through difficulties in human, social and industrial affairs. Examples include the dramatic situations of the release of the atomic bomb in 1945, the Space Shuttle Challenger destruction in 1986, the tsunami in Indonesia in 2004, and the Lehman Brothers bankruptcy in 2008.

These dramatic situations, hereafter situations, show that human beings experience situations that are diverse in nature and context, yet they feature one key phenomenon: the lack of needed information. The central challenge in this research is to understand why such situations emerge. The discussion of this challenge is carried on by exploring the role of information in dramatic situations as a source of unwanted consequences, along with its importance in human life.

Situations like these are concerned with decision-making processes and require a rational behaviour to process information related to them [1]. Philosophers, scientists 
and industrialists hypothesize about information problems and intend to develop theories or solutions that are partially helpful [2], [3], [4].

Information has a deep impact on personal well-being, decision-making processes, innovation and production [5], [6]. But, the failure to achieve balance between the surging volumes of information we access (mostly affected by electronic information) and its obverse, information underload [7]. Our everyday experiences manifest numerous instances in which information is the key characteristic that generates various consequences, many of which are experienced as failures or fatalities. Therefore, in this paper a core phenomenon is explored: the lack of needed information in human, social and industrial affairs.

The lack of needed information is understood as a composition of different behavioural aspects on the part of human agents that have implications for the production, the transfer or the use of information in a specific context. Although related topics have tackled similar phenomena for some decades now [5], [6], [7], [8], [9], there is little we understand about it. Indeed, there is no comprehensive understanding that has tackled such a phenomenon at length.

The objective of this paper is to give an understanding of the phenomenon of the lack of needed information by developing a model that intends to explain the causes of the lack of needed information that contribute to unwanted consequences. Empirically, the exploration of this phenomenon is based on the grounded theory approach [10] which has since been further developed [11], [12], [13].

The paper is organized as follows. First, a background and motivation is presented. Then, an overview of grounded theory approach is provided. Furthermore, the application of the grounded theory approach (based on a coding process) and a model derived from data analysis are presented. Finally, the paper describes some practical and theoretical implications that may advance studies with a focus on the lack of needed information and its impact on organizations and societies.

\section{Background and Motivation}

Situations, such as a global financial crisis or a tsunami catastrophe, are the focus of this research. Hence, the intention is to explore and understand the phenomenon of the lack of needed information. Such situations present various experiences that are dependent on information practices. These practices are understood as processes that govern decision-making, which mainly developed during the information revolution [5], [6], [7], [14]. The information revolution can be understood as an era in which technological breakthroughs have profoundly transformed human behaviour and cultures, and which provided the foundations for the establishment and development of the information society [15], [16]. In practical terms, scholars call for joint efforts to try to resolve the dark side of the information revolution [6], mainly represented by information overflow, which is affected by electronic information that negatively affects productivity and creativity [5].

The information society that developed through the information revolution seems to have no safeguards [17]. It concerns information that offers to human beings "new 
and unparalleled opportunities to create novel social networks, new cultural configurations with innovative ideas, commitments and aspirations, and also new political structures" [17]. Apart from this, the information revolution implies reshaping the material basis of the information society [16]. It is suggested that this is a movement that has been enormously visible during the post-industrial society, in which it is said that humans receive more information than ever before [18]. There are many unresolved issues that still question what an information revolution implies for our assumed information society. Are we really getting enough information? If so, what kind of information is it? Also, how is it possible that there are still many restricted channels of communication, which may hold some of the most important information? Consider the two following situations, which have been selected for the purpose of explicating typical situations where the lack of needed information has occurred, and where ICT infrastructures have failed to spread information to the public at the needed time.

The tsunami natural disaster in Indonesia occurred in December 2004 and claimed thousands of lives around the Indian Ocean. Activated by a 7.7 Richter scale undersea earthquake with its epicentre in the Indian Ocean, the tsunami was a tremendous natural disaster that happened unexpectedly and without any warnings being sent to civilians. In fact, the United Nations Education, Scientific and Cultural Organization (UNESCO) has declared that the Pacific Tsunami Warning Centre (PTWC) in Hawaii did detect the Java region tsunami. But, due to gaps in broadcasting critical information to the public, no warnings were sent on time, which otherwise could have saved thousands of lives. Seismological centres worldwide usually spread rapid information to the public about any earthquake detection, but failed to reach citizens in this situation. The signs of the Indian Ocean tsunami were first picked up by the PTWC in Hawaii, 17 minutes after the earthquake but before the tsunami hit the coast of Java. Its immediate response was a warning message transmitted to its Jakartan colleagues, who also informed 400 Indonesian authorities. However, there was little they could do. Sadly, they claimed that there were no alarms, no emergency broadcasts or breaking news information transmitted through radio or television; and there was just no way to reach the public on the coast. The Hawaiian PTWC argued that it was the Indonesians' responsibility to inform the public. So what went wrong in this situation? Why did all the possible communication channels fail to deliver information on time?

History then repeated itself. Indonesia was struck again by a powerful tsunami in October 2010. Witnesses have described this tsunami as being like a "runaway train". The only thing they could do was to run as far away from the shore as they could. Unfortunately, many people did not escape and, as a result, perished. This tsunami was registered for the first time by the PTWC in Hawaii, and the official tsunami warnings that went out after the quake either arrived too late or not at all in those communities that were most at risk. Many survivors have said that they were totally unprepared when the three metre high wall of water swept in over land. But why did information fail to inform the public a second time? Was the region not prepared for this situation as a result of the detecting system established after the tsunami catastrophe in December 2004? 
The key concern in such situations is to understand what really causes the lack of needed information. Answers to this concern have been investigated from an array of studies mostly concentrated on the area of information management. Theoretical fields of information logistics [19], information literacy [20] and information behaviour theories [21] show that their theories, concepts and aspirations focus on problems generated by the lack of needed information. However, these theoretical fields that claim to successfully explain or solve information-related problems show that their ambitions can only provide a partial understanding of what causes the lack of needed information. These theories indicate that they cannot truly account for the phenomenon of the lack of needed information. The implications of such theories have led to the understanding that the phenomenon of the lack of needed information remains unexplored and requires thorough investigation. Thus, there is no comprehensive a priori theory to be used for the design of an empirical investigation. In this study, therefore, it was necessary to continue with an analytical approach - empirically oriented - that is presented in the next section.

\section{Empirical Investigation: A Grounded Theory Approach}

A number of authors have developed theories that postulate how problems connected with information in human affairs arise in different circumstances [2], [5], [14], [22]. These problems may be caused by different factors, among which are the management factor, the political factor or the ethical factor, e.g. [5], [7]. In practice, information is considered as an invaluable asset in three core organizational processes engaged in communication: (a) information production; (b) information exchange; and (c) information receipt [23].

Communication in organizational processes is often followed by unprecedented difficulties that result in the failure of successful management of information-related practices [7], [24]. Recent investigations, especially those of the last two decades, have documented different information-related problems that occur in an unexpected fashion [9].

By systematically applying a grounded theory approach, this study finds an explanation for how the phenomenon of the lack of needed information arises in human, social and industrial affairs. Details related to the empirical findings are presented below.

\subsection{A Summary of Selected Empirical Cases}

In this study, data collection and analysis are based on secondary sources. All the data have been collected from news reports that were carefully reviewed in order to derive an understanding of why the lack of needed information emerged in these cases. The collection resulted in fifty empirical cases (see [26] for more details on case description and news sources). The vast majority of the empirical cases selected have occurred during the last two decades. However, this selection is driven by the accessibility of data on the Internet, which covers the selected cases much more comprehensively compared to 
cases that emerged before the Internet existed. The data analysis was conducted using open coding, axial coding and selective coding, which were adapted for the purpose of this research according to procedural aspects illustrated by [27], and enhanced by [11], [12], [13].

The fifty empirical cases comprise different situations that are selected for the purpose of emphasizing the phenomenon of the lack of needed information. More concretely, the selected situations are grouped as follows: Natural Disasters (9); Environmental Disasters (6); Financial Failures (7); Health Failures (6); Political Scandals (6); Conflict Situations (3); Engineering and Technological Failures (8); Nuclear and Chemical Disasters (5). The fifty cases identified are analyzed using a grounded theory approach. They are categorized in an a priori manner, solely for the purpose of facilitating the reader's understanding of what situations have been taken into consideration. However, this categorization does not have any influence on the empirical analysis.

\subsection{Research Approach: Analysis and Results}

Data analysis emerged iteratively, starting with early open-ended research, primarily line-by-line text analysis, and continued with more strategic selection of emerging concepts and categories [11]. The benefit of the iterative process is that the initial phase of exploration followed a flexible path in terms of understanding and collecting data, while the later phase of conceptualization followed a more strictly organized path based on the strategic planning of analysis.

The coding process as formulated by the grounded theory approach is employed more formally in data analysis after all the data have been collected, selected and refined. The analyses were based on three types of coding presented by [27], which are: open coding, axial coding, and selective coding.

The actual conceptualization and interpretation of the phenomenon of the lack of needed information became clear in the early phase of data analysis. The conceptualization of fifty cases developed on the basis of analyzing each case to derive characteristics that could show the causes of the lack of needed information. The results of such a conceptualization were mainly dependent on several codes that were identified as recurring in many situations. For instance, codes such as "did not alert" or "warning system(s)" were crucial for interpreting the phenomenon in context. The use of the majority of codes clearly presented significant similarities in all the situations, resulting in an early, yet crucial, interpretation of the phenomenon in context.

Axial coding continued with constant comparative analysis of the data. Codes found in the data became more meaningful when they continued to be merged, changed, and even eliminated. The codes that were merged represented a type of code used to show a key input for the purpose of generating categories. The codes that were changed were adapted to other similar codes, which may have reduced redundancy. The eliminated codes were primarily redundant. With axial coding, the analysis process led, firstly, to a refinement of the identified codes and induction of concepts. 
The axial coding analysis was based on classifications, and comparative analysis resulted in the identification of eight sub-categories. As a result, the comparative analysis showed two main differences between the eight identified sub-categories. The differences resulted in grouping the sub-categories by introducing two main axial categories, i.e. information lack and information overflow, based on the following definitions:

\section{Information Lack}

1. Information is non-existent - is characterized by failure to communicate information in situations when actions are unforeseen and the responsible body for transmitting information is unaware of such a need, usually due to mismanagement.

2. Information is insufficient - is characterized by failure to communicate on-time information as a result of pre-planning of circumstances that may cause unwanted results in a specific situation. Lack of awareness, mismanagement and difficulty in understanding represent failure to act in a timely fashion.

3. Information is censored - is characterized by serious violation of information. Such information is usually hindered intentionally, secretly and illegally for the purpose of suppressing original information that is intended for the people and that may be significant for people's needs. Fraud is one of the key acts that reflect the censoring of information.

4. Information is undelivered - is characterized by incompetent acts of humans, with a dual outcome. The act is either undertaken intentionally by prohibiting the use of information or the undelivered information is caused by lack of awareness.

\section{Information Overflow}

5. Information is ambiguous - is characterized by lack of control of information. It is usually accompanied by miscalculations and lack of accurate evidence that misleads important decision-making processes.

6. Information is redundant - is characterized by duplication or even multiplication of the same information (repetition of information's message in synonyms or with the same excessive expression) due to lack of control or lack of awareness.

7. Information is irrelevant - is characterized by types of information that have no validity and are shared by unknown sources. Such information holds misinterpretations.

8. Information is undervalued - is characterized by mismanagement that may cause misinterpretation of information, possibly by lack of awareness or lack of awareness.

A significant number of codes, both substantive and theoretical, that are ultimately used in generating the eight sub-categories have been recurrent in one or more of the sub-categories, as presented in figure 1.

Selective coding is employed as the final step required to generate the core category, ultimately to generate a middle-range theory, which represents an initial outline for a possible future theory [13]. The data analysis has developed the core category by 
verifying that the phenomenon of the lack of needed information is evident in practical senses. Thus, the core category as a result of analysis is named in this study "information inadequacy". With the core category at hand, the aim is to integrate all the analysis into one formulated comprehensive outline that could portray the phenomenon of the lack of needed information.

Analyses generated new and interesting results that are used to formulate an explicit meaning of what is characterized as "information inadequacy," and which is defined as follows: "dramatic situations (many of which happen on a daily basis) that encounter information as the key resource in different situations and circumstances, manifest various consequences, many of which are experienced as failures and fatalities in human, social and industrial affairs."

Figure 1 illustrates the process of developing substantive and theoretical codes that lead to the creation of concepts. The concepts consist of various sub-categories that can be classified into two main categories that, in turn, can be brought together in a single category.

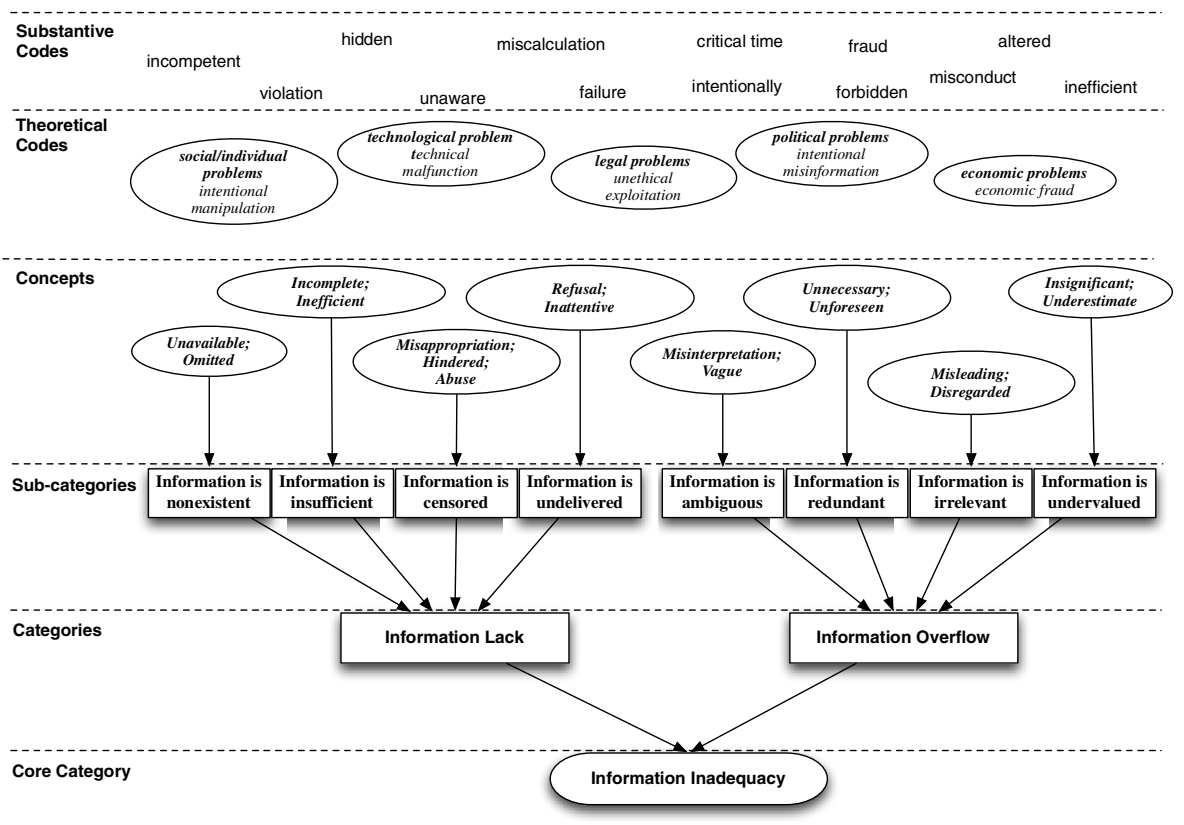

Fig. 1. Results from the Coding Process (Open Coding, Axial Coding, Selective Coding) leading to the development of the core category "Information Inadequacy"

\section{Discussion and Conclusion}

This study has proposed an initial outline of information inadequacy that resulted from the need to understand the phenomenon of the lack of needed information. 
Initially, this study found that theoretical fields that claim to handle the phenomenon of the lack of needed information cannot account for, explain, or suggest a remedy for the dramatic situations where there is a lack of needed information. They can only account for a partial and, hence, a limited understanding of the phenomenon in context.

A need for empirical investigations thus became crucial. It triggered new explorations in interpreting what is changing about today's information access and what remains critical in global information landscapes (these may vary from social, political, economic or environmental contexts). The empirical investigation was based on a grounded theory approach applied to a collection of fifty empirical cases. This investigation resulted in the identification of characteristics, patterns and causes of how the needed information fails to reach the intended person at the right time and place, causing unwanted and even disastrous consequences. The analysis suggested that information-related problems of this nature appear mainly due to difficulties that are caused by the information source (sender) and information mediator - whether human or machine. The results of this investigation have developed an initial outline of information inadequacy that could guide the development of a future theory of information inadequacy.

The grounded theory approach became instrumental in this study. The development of an understanding of the phenomenon in context is achieved by suggesting that a number of characteristics (information is ambiguous, information is non-existent, information is redundant, and the like) and their interrelationships present various patterns (described as information inadequacies) that emerge in a communication process. These are followed by a number of diverse factors, ranging from political and cultural structures, through human individual capabilities, that culminate with procedural and technological artefacts and that influence the increase in consequences.

In practice, the proposed concept of information inadequacy addresses all human beings who are concerned with information in their everyday practices and intend to enhance their time by carefully managing information. More importantly, information inadequacy can act as a diagnosis tool that allows industrialists, technology developers, environmentalists and others to consider how to enhance information communication in the future. It is justifiable, as well as moderate, to state that information inadequacy as such is not taken as seriously as a problem in our current information society, and that it is usually accompanied by unwanted consequences.

Given the results of the empirical investigation conducted here, the identified factors indicate how hindrances to information provision may be used as guidelines for the diagnosis and re-design of information provision processes. In short, this would imply that each pattern of information inadequacy identified might be used to direct new and innovative diagnostic and re-design teams that focus on information management and on the more careful planning of information flows that are present and important in dramatic situations. Such an understanding may possibly guide further development of a future theory of information inadequacy that can be instrumental in developing more efficient information systems for organizations and societies and for an operational use of information. 
Apart from realizing that a digital future may seem promising, information inadequacy remains a challenging dilemma that will continue to rely on human or machinebased communication. The current results that present an initial outline of information inadequacy can be developed in at least three dimensions: (i) further development of the content that represents information inadequacy, i.e. factors and their interrelations; (ii) the empirical validity of the current elaboration, based on a very large number of cases (e.g. 1,000); (iii) the research object, i.e. not only "dramatic situations" but also the "everyday situations". These can be studied by looking more concretely at sociopsychological factors and technological factors that today are regarded as crucial aspects that affect information inadequacy.

\section{References}

1. Newell, A., Simon, H.A.: Human problem solving. Prentice-Hall, Englewood Cliffs (1972)

2. Akerlof, G.: The market for 'Lemons': quality uncertainty and the market mechanism. Quart. J. Econ. 84, 488-500 (1970)

3. Bandura, A.: Self-efficacy: toward a unifying theory of behavioral change. J. Psych. Rev. 84, 191-215 (1977)

4. Ennals, R., Stratton, L., Moujahid, N., Kovela, S.: Global information technology and global citizenship education. AI \& Soc. 23, 61-68 (2009)

5. Dean, D., Webb, C.: Recovering from information overload. McKinsey Q (2011)

6. Hemp, P.: Death by information overload. Harvard Bus. Rev. (2009)

7. O'Reilly, C.A.: Individuals and information overload in organizations: is more necessarily better? The Acad. Manag. J. 23, 684-696 (1980)

8. Creese, G.: Information scarcity to information overload. Info., Manag., Magaz, 20-22 (2007)

9. Ojala, M.: Transforming information quality 33 (2009) Online

10. Glaser, B., Strauss, A.L.: The discovery of grounded theory: strategies for qualitative research. Aldine, Chicago (1967)

11. Orlikowski, W.J.: CASE tools as organizational change: investigating incremental and radical changes in systems development. MISQ 17, 309-340 (1993)

12. Sarker, S., Lau, F., Sahay, S.: Using an adapted grounded theory approach for inductive theory building about virtual team development. The Database for Adv. IS 32, 38-56 (2001)

13. Charmaz, K.: Constructing Grounded Theory: A Practical Guide Through Qualitative Analysis. Sage Publications, Thousand Oaks (2006)

14. Eppler, M.J., Mengis, J.: The concept of information overload: a review of literature from organization science, Accounting, Marketing, MIS, and Related Disciplines. Info Soc. 20, 325-344 (2004)

15. Boyd, D.: Taken Out of Context: American Teen Sociality in Networked Publics (Doctoral Dissertation). University of California- Berkley Press (2008)

16. Castells, M.: The Power of Identity: The Information Age: Economy, Society and Culture, 2nd edn. Wiley-Blackwell, Chichester (2010)

17. Haftor, D.M., Mirijamdotter, A., Kajtazi, M.: In search for unity within the diversity of information societies. In: Haftor, D.M., Mirijamdotter, A. (eds.) Information and Communication Technologies, Society and Human Beings: Theory and Framework, pp. 540-546. IGI Publishing, New York (2010) 
18. Lonsdale, J.D.: The nature of war in the information age. Routledge, New York (2004)

19. Haftor, D.M., Kajtazi, M., Mirijamdotter, A.: A Review of Information Logistics Research Publications. In: Abramowicz, W., Maciaszek, L., Węcel, K. (eds.) BIS Workshops 2011 and BIS 2011. LNBIP, vol. 97, pp. 244-255. Springer, Heidelberg (2011)

20. Bruce, C.: Informed Learning. Association of College and Research Libraries (2008)

21. Fisher, E.K., Erdelez, S., McKechnie, L. (eds.): Theories of Information Behavior, 2nd edn. American Society for Information Science and Technology, New Jersey (2006)

22. Mingers, J.C.: Information and meaning: foundations for an intersubjective account. J. IS 5, 285-306 (1995)

23. Mortensen, C.D. (ed.): Communication theory, 2nd edn. Transaction Publishers, New Jersey (2009)

24. Hwang, M.I., Lin, J.W.: Information dimension, information overload and decision quality. J. IS 25, 213-219 (1999)

25. Bawden, D., Robinson, L.: Training for information literacy: diverse approaches. In: Proceedings of the International Online Information Meeting, London (UK), pp. 87-90. Learned Information Europe Ltd., Oxford (2001)

26. Kajtazi, M.: An exploration of Information Inadequacy: Instances that cause the lack of needed information. Licentiate Thesis, School of Computer Science, Physics and Mathematics, Linnaeus University, Växjö, Sweden (2011)

27. Strauss, A., Corbin, J.: Basics of qualitative research. Sage Publications, Newbury Park (1990) 